\title{
Foraging Behavior of Bottlenose Dolphins in the Shannon Estuary, Ireland as Determined through Static Acoustic Monitoring
}

\author{
Mathijs Carmen ${ }^{1, *}$, Simon D. Berrow ${ }^{1,2}$ and Joanne M. O'Brien ${ }^{1,2, *(D)}$ \\ 1 Marine and Freshwater Research Centre, Galway-Mayo Institute of Technology, Dublin Road, \\ EC5 855G Galway, Ireland; simon.berrow@iwdg.ie \\ 2 Irish Whale and Dolphin Group, Merchants Quay, V15 E762 Kilrush, Ireland \\ * Correspondence: mathijscarmen01@hotmail.com (M.C.); joanne.obrien@gmit.ie (J.M.O.); \\ Tel.: +32-494-99-15-23 (M.C.)
}

Citation: Carmen, M.; Berrow, S.D.; O'Brien, J.M. Foraging Behavior of Bottlenose Dolphins in the Shannon Estuary, Ireland as Determined through Static Acoustic Monitoring. J. Mar. Sci. Eng. 2021, 9, 275. https:// doi.org/10.3390/jmse9030275

Academic Editor: Jorge

M.S. Gonçalves

Received: 6 January 2021

Accepted: 23 February 2021

Published: 4 March 2021

Publisher's Note: MDPI stays neutral with regard to jurisdictional claims in published maps and institutional affiliations.

Copyright: (c) 2021 by the authors. Licensee MDPI, Basel, Switzerland. This article is an open access article distributed under the terms and conditions of the Creative Commons Attribution (CC BY) license (https:/ / creativecommons.org/licenses/by/ $4.0 /)$.

\begin{abstract}
The Shannon Estuary in Ireland is home to a resident population of bottlenose dolphins (Tursiops truncatus) and is designated as a Special Area of Conservation under the EU Habitats Directive. It is an important industrial area, with numerous deep-water berths for shipping. Despite its high conservation value, there are few published studies on habitat use or foraging behavior of the Shannon dolphins throughout the year. The present study assessed the year-round presence and foraging activity of bottlenose dolphins at different locations in the middle and inner estuary using static acoustic monitoring. Dolphin presence was found to decrease with increased distance from the estuary mouth, i.e., where the estuary meets the Atlantic Ocean, while at the same time, foraging was found to be considerably higher in the upriver areas, suggesting the inner estuary was an important foraging area. Model predictions for seasonal, tidal and diel foraging were highly variable across locations, indicating that changes in dolphin behavior occurred over relatively small geographical scales. These results indicate that conservation efforts should consider the Shannon Estuary as a dynamic aggregation of habitats and future development initiatives should attempt to mitigate disturbance to the dolphins during important foraging periods on seasonal and diel scales.
\end{abstract}

Keywords: bottlenose dolphin; C-PODs; deep-water berths; special area of conservation

\section{Introduction}

The bottlenose dolphin, Tursiops truncatus, is one of 25 cetacean species recorded to date in Irish waters [1,2]. They are protected under the European Union (EU) Habitats Directive (1992), which requires strict protection of these species of community interest (Annex IV) and their habitats across their entire range within the EU. Furthermore, they are listed under Annex II of the Directive, which requires member states to protect them and maintain them at a favorable conservation status requiring the designation of Special Areas of Conservation (SAC) for this species [3,4]. The Shannon Estuary (Lower River Shannon, Site Code 002165) is one of only two designated SACs for bottlenose dolphins in Ireland [4-6].

The Shannon Estuary is a large estuarine complex forming the connection between the River Shannon and the Atlantic Ocean [7,8] and extends for over almost $100 \mathrm{~km}$ from Limerick city in the east to the estuary mouth, i.e., the connection with the ocean, in the west [3]. The bottlenose dolphins found in the estuary are unique as they are resident year round, and genetically distinct from other Irish populations [6,9]. Historical data suggests that the dolphins in the Shannon Estuary have been present since at least 1835 [10]. This resident population predominantly uses the SAC as well as Tralee and Brandon Bays, an area about $30 \mathrm{~km}$ southwest of the estuary mouth, as their main habitats [4,11,12]. The most recent population size estimate of the Shannon dolphins in 2018, with an estimated summerautumn abundance of $139 \pm 15$ individuals [13], is consistent with earlier estimates [3,4,14-16], indicating the relative stability of the dolphin population [4]. 
Although being one of the most important habitats for dolphins in Ireland, the Shannon Estuary is also one of Europe's most important deep-water berths with up to 1000 ships using the estuary annually $[8,17]$. The Shannon Estuary has several economic and industrial functions and is a popular area for marine tourism and recreation [8]. This exposes the Shannon dolphins to a number of potential anthropogenic influences such as pollutant contamination, habitat degradation, acoustic disturbance, entanglement in fishing gear and physical disturbance from large ships and whale watching boats $[3,7,18]$.

Bottlenose dolphins use vocalizations during various behaviors [19], which can be classified across three distinct categories: tonal whistles, burst-pulse sounds and echolocation clicks $[19,20]$, the latter being the one of interest in this study. Echolocation clicks, in general, are high frequency, broadband clicking sounds of short duration and are mainly used for orientation and foraging [20-22]. Peak frequencies of bottlenose dolphin clicks range from 30 to $150 \mathrm{kHz}$ with source levels up to $228 \mathrm{~dB}$ (re $1 \mu \mathrm{Pa}$ at $1 \mathrm{~m}$ ) [20,23].

Bottlenose dolphins are generalist predators with a very broad diet [24,25] and the dolphins off the west coast of Ireland are known to feed on a wide range of demersal and pelagic fish species $[18,25,26]$. A dedicated study on foraging behavior and diet composition of the Shannon dolphins has not yet been carried out, but the dolphins have been observed feeding co-operatively on shoaling fish $[3,18]$ most often during periods of ebbing tides $[3,7,27]$, which is thought to increase prey encounters [3].

The present study is the first attempt to describe the year-round presence and foraging behavior of bottlenose dolphins at a number of sites in the Shannon Estuary and provides some of the only data on the use of the inner estuary by dolphins. Previous research has focused on abundance and social structure of dolphins within a restricted timeframe between March and November and restricted geographically to the outer and middle part of the estuary. Only a single study [28] reported on the upriver winter distribution of bottlenose dolphins while one study [16] carried out summer and winter transects in the middle and outer estuary. Prior to the current study, only anecdotal information on the foraging behavior of these dolphins existed. Areas with high tidal flow and slope were identified as important foraging areas but this was based solely on visual observations [7]. Results from the present study are critical to our understanding of how dolphins use the estuary and to highlight potential foraging hotspots. This can contribute towards effective conservation management of the dolphins, especially if the estuary is subjected to increased shipping through harbor developments and new industries as highlighted in the Shannon Integrated Framework Plan, an initiative driven by Clare, Kerry and Limerick County Council, Limerick City, Shannon Development and Shannon Foynes Port Company [8].

\section{Materials and Methods}

The study was conducted within the Lower River Shannon SAC (Site Code 0002635), located on the western seaboard of Ireland, bordered by Counties Clare, Kerry and Limerick. Static acoustic monitoring (SAM) using C-PODs was conducted from 2009 until 2015 at four distinct locations in the Shannon Estuary (Figure 1), at Moneypoint in the middle estuary and Foynes, Aughinish and Shannon Airport in the inner estuary.

The deployment period and days monitored for each location are presented in Table 1. SAM using C-PODs involves the detection of cetacean echolocation clicks, whereby the acoustic monitoring gear is statically positioned in the water column [29]. The C-POD, manufactured by Chelonia Limited (Mousehole, Cornwall, United Kingdom), is an acoustic monitoring device that, once deployed, operates passively at sea, detecting click trains within the frequency range of 20 to $160 \mathrm{kHz}$. When a click is detected, the C-POD records various parameters like time of occurrence, duration, sound pressure level, frequency and bandwidth of the click as well as the water temperature $[29,30]$. It is important to note that C-PODs do not record actual sound files, but only the informative parameters of the clicks and click trains $[29,30]$. The data are stored on an internal SD flash card and can be processed with the software provided by Chelonia Ltd. 


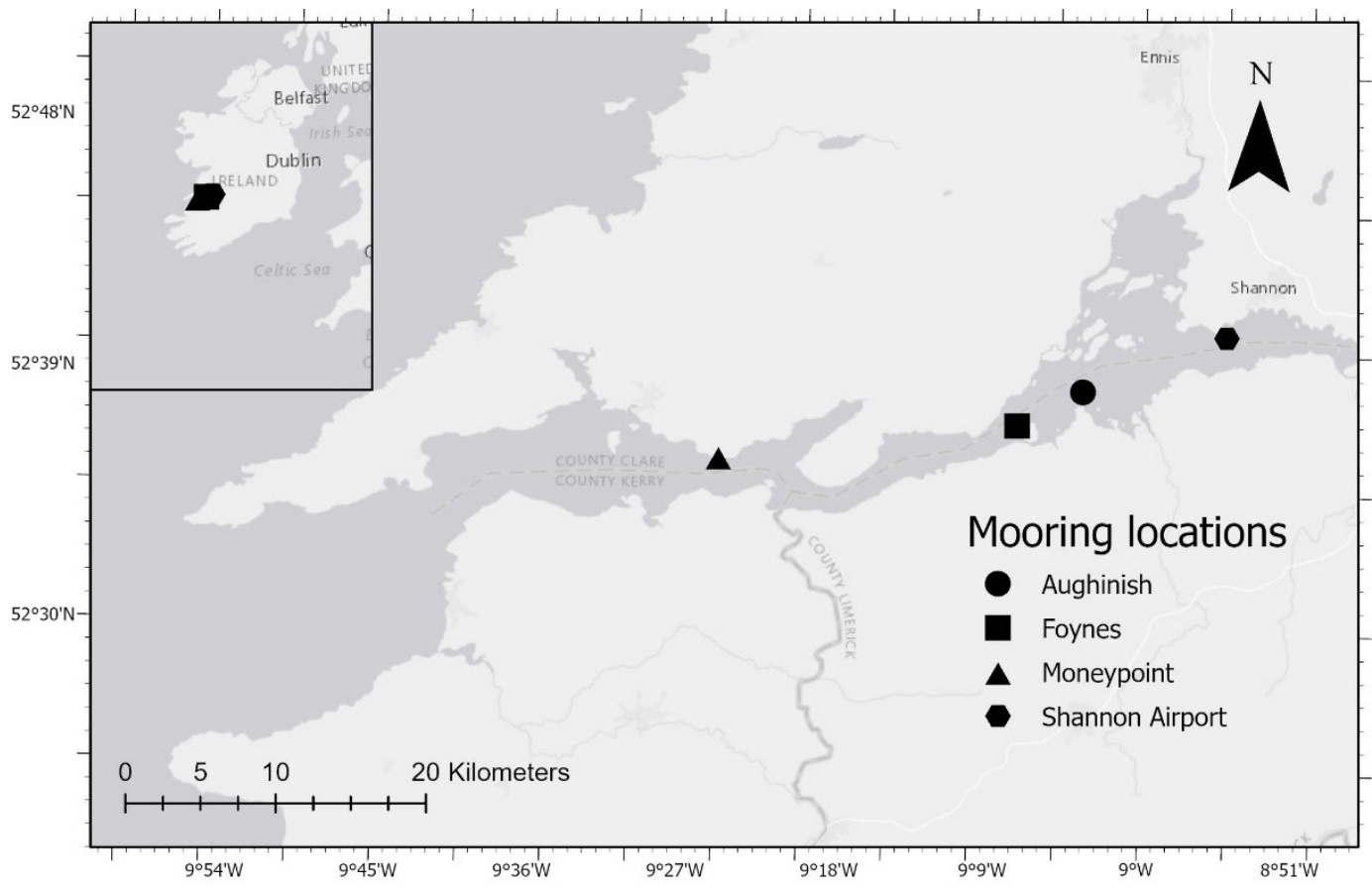

Figure 1. Map of the Shannon Estuary with the locations of C-POD deployment.

Table 1. Monitoring period and days monitored for every location.

\begin{tabular}{ccc}
\hline Location & Monitoring Period & Days Monitored \\
\hline Moneypoint & $2009-2015$ & 1720 \\
Foynes & $2009-2014$ & 1428 \\
Aughinish & $2011-2014$ & 812 \\
Shannon Airport & $2011-2013$ & 738 \\
\hline
\end{tabular}

A total of 24 different C-POD units, i.e., with different C-POD IDs, were used during the present study, with some units being used multiple times at multiple locations. The C-PODs were moored to existing structures close to shore and equipped with small salmon floats to help keep them vertical during strong tidal flows. The depth at the monitoring sites ranged from around $15 \mathrm{~m}$ at Shannon Airport to $20 \mathrm{~m}$ at Moneypoint and 20+ $\mathrm{m}$ at Aughinish and Foynes and the devices were always positioned at mid-water depths. All units were calibrated prior to deployment at Moneypoint jetty as part of a previous study [29].

The echolocation parameter required to detect foraging through SAM is the inter-click interval (ICI), the time between two successive clicks in a click train [29]. Since ICIs in trains are not constant, the minimum ICI (minICI) of a click train is often used [31,32]. These minICIs vary according to different behaviors and when cetaceans explore their surroundings at a short distance during foraging, they produce shorter and faster clicks, i.e., with shorter minICIs $[20,31]$. In the final stages of prey capture, these fast clicks are called feeding buzzes and predominantly have minICIs $<10 \mathrm{~ms}[20,31]$, therefore Carlstrom (2005) proposed that a minICI shorter than $10 \mathrm{~ms}$ is a good proxy to classify click trains as foraging [31]. This $10 \mathrm{~ms}$ threshold value has been used in several behavioral studies of multiple odontocete species $[22,29,31,33,34]$ and was also used in the present study.

The dedicated software provided by Chelonia Ltd. (C-POD.exe, downloaded from chelonia.co.uk) allows the recorded click train data to be viewed, analyzed and exported for further analysis. The software is able to automatically detect click trains and allows extraction of the trains classified under five types: Narrow Band High Frequency (NBHF) clicks, dolphin clicks, boat sonars, other click train sources and unclassified clicks [29], with the dolphin clicks being the ones of interest. When the data from the SD card is read into the software, the click trains are automatically classified into four quality classes according 
to their likelihood of being correctly identified as cetacean click trains. During this study, only the dolphin clicks classified in the two highest quality classes (high and moderate) were used, with the doubtful click trains being discarded.

When exporting the train details, several ICIs were exported for each train, but for this study only the minICI of each train was of interest, and unnecessary values were removed. Subsequently, the identification numbers of the C-PODs (C-POD ID) were added to the data as well as several informative parameters in order to investigate their influence on foraging behavior. These parameters were season, diel phase, tidal cycle and tidal phase and they were added using the date and time of each click train detection and corresponding minICI.

Season consists of four factors, namely winter, spring, summer and autumn and in this study they are defined as the periods from November till January, February till April, May till July, and August till October, respectively. Diel phase encompasses the different phases of a single day, i.e., morning, day, evening and night. Sunrise and sunset data were obtained from the United States Naval Observatory (USNO) website (usno.navy.mil/USNO/astronomical-applications) and for each individual data point, the corresponding diel phase was added. Morning, for example, is a 3-h period around the hour of sunrise. When the sun rises at 5:17 a.m., for example, the hour of sunrise is between 5 and 6 a.m. and the morning phase is defined as the 3-h period around this, i.e., from 4 till 7 a.m. The same goes for the evening, i.e., a 3-h period around the hour of sunset. Day and night are the periods in between.

The tidal cycle includes ebb, flood, slack high and slack low. Ebb and flood are the periods when the sea level lowers and rises, respectively. Slack high is the period around high tide, when there is less water movement, while slack low is the same period around low tide. Slack high and slack low are 3-h periods around the hour of high tide and low tide, respectively, and apply the same defining strategy as explained above for morning and evening. The WXTide32 software (downloaded from wxtide32.com) was used to consult the relevant tide tables.

Finally, spring tide, neap tide and transitional phase are the factors of the tidal phase, i.e., tidal fluctuations on a larger temporal scale. Tidal heights fluctuate on a fortnightly basis and when the differences in tidal height between high and low tide are the largest, this is called a spring tide event. The factor spring tide in this study is a 3-day period defined as one day on each side of the day of the spring tide event. When the differences in tidal height are the smallest it is called a neap tide event and the factor neap tide is defined in the same way as the spring tide. The transitional phase is defined as the period in between the spring and neap tide periods.

The use of the monitoring locations as foraging habitats by bottlenose dolphins was analyzed statistically using the four variables; season, diel phase, tidal cycle and tidal phase, as predictors of foraging behavior. MinICIs $<10 \mathrm{~ms}$ were used as a proxy for foraging, and the minICI response variable was transformed to a binomial variable with $\operatorname{minICI}<10 \mathrm{~ms}$ classified as foraging (1) and minICI $>10 \mathrm{~ms}$ classified as non-foraging (0). The statistical analysis was carried out using the program RStudio Version 0.99.489 (RStudio, PBC).

A generalized linear mixed model (GLMM) was fitted to the binomial data using the glmer function in the lme4 package. A mixed model was chosen to account for possible variation in sensitivity between C-POD units. C-POD ID was included as a random factor, while season, diel phase, tidal cycle and tidal phase were included as fixed factors. Akaike's information criterion (AIC) [35], histograms of fitted residuals and comparative Chi-Square tests using the ANOVA function of the stats package were used for model selection. First, models were fitted to the data with each explanatory variable separately, after which the AIC values were compared to identify the most important single variable. Subsequently, a stepwise procedure was conducted for building the models, starting with the variable identified in the previous step and adding variables one at a time. When adding a variable did not significantly contribute to a better fit of the model, the simpler model was chosen. After model selection, the overall effect on the response of each variable included in the 
final models was investigated by carrying out a loglikelihood ratio test (LR test) between the full model and the model without the parameter of interest.

Finally, predictions for proportions of dolphin click trains with a minICI $<10 \mathrm{~ms}$, i.e., foraging trains, were extracted across all levels using the predict function of the stats package and presented as boxplots using the HH package [36] to visually support the modeled relationships between the explanatory variables and the response variable. Predicted proportions of foraging trains can be understood as an approximation of time or effort spent on foraging by dolphins in this study and therefore the preferred use of the shortened term 'predicted foraging' in the results and discussion of this manuscript

\section{Results}

A total of 71,054 click trains were recorded between 2009 and 2015 across four different locations in the Shannon Estuary. The frequency distribution of the minICI is presented in Figure 2. It has two distinct peaks, one of very short ICIs less than $5 \mathrm{~ms}$ and another of ICIs around $85 \mathrm{~ms}$. Based on this distribution and following previous studies, a minICI $<10 \mathrm{~ms}$ was chosen as a proxy for the foraging behavior of bottlenose dolphins in the Shannon Estuary $[20,31]$.

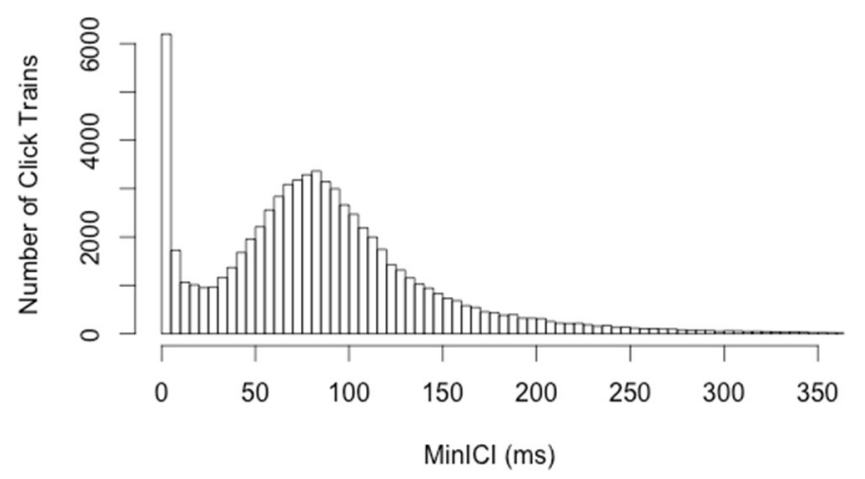

Figure 2. Histogram of minimum inter-click intervals (minICIs) for bottlenose dolphin click trains in the Shannon Estuary.

A total of 7922 click trains recorded in the Shannon Estuary were classified as foraging, accounting for $11 \%$ of the total number of trains recorded during the present study.

\subsection{Moneypoint}

The majority of the click trains in this study were recorded at Moneypoint, during a total of 1720 monitoring days between January 2009 and October 2015. C-PODs detected dolphin click trains on 1224 different days adding up to $71.2 \%$ of days monitored (Figure 3). A total of 42,954 click trains were recorded, with 3155 click trains (7.3\% of total) classified as foraging (Figure 4). Interestingly, a total of $63 \%$ of total trains recorded at this location were during nighttime, suggesting higher acoustic activity of bottlenose dolphins occurred during this period.

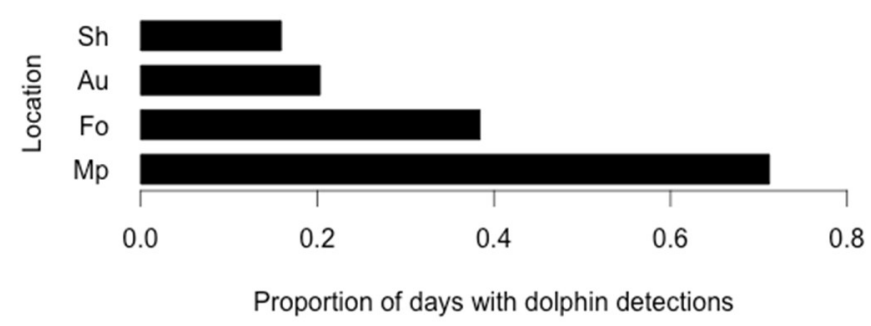

Figure 3. Summary of the proportion of days with dolphin detections per location across their respective study periods $(\mathrm{Mp}=$ Moneypoint, $\mathrm{Fo}=$ Foynes, $\mathrm{Au}=$ Aughinish and $\mathrm{Sh}=$ Shannon Airport $)$. 


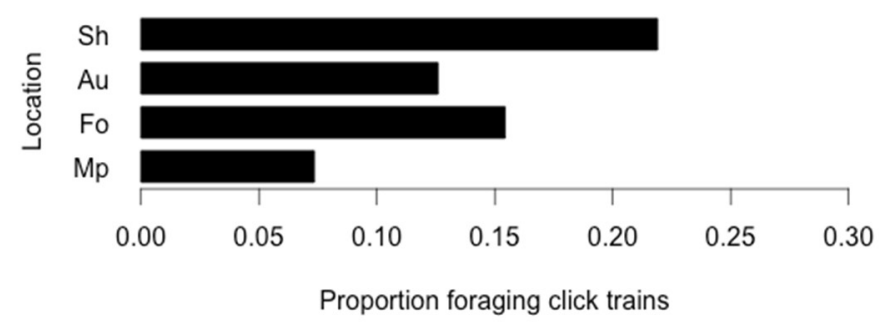

Figure 4. Summary of the proportion of trains classified as foraging for each location ( $\mathrm{Mp}=$ Moneypoint, Fo = Foynes, $\mathrm{Au}=$ Aughinish and $\mathrm{Sh}=$ Shannon Airport).

The stepwise model selection for Moneypoint is presented in Appendix A (Table A1). Starting with the model including only tidal cycle as a fixed factor and C-POD ID as a random factor, adding the other variables significantly improved the model each time according to the comparison of AIC values and comparative Chi-Squared tests (Table A1). Therefore, the model that best fitted the binomial foraging data from Moneypoint contained all four variables of interest (season, tidal phase, tidal cycle and diel phase). Details of this model are given in Table 2. The predicted foraging across the variables included in the model is presented as boxplots to visually support the modeled relationships between the variables and foraging (Figure 5).

Table 2. Final model for Moneypoint ( $n=42,954$ minICIs of which 3155 classified as foraging. Recorded by 13 different C-POD units). Estimates with standard errors (SE) and odds ratios (OR) of the variables included in the model. $\Sigma^{2}$ is the variance of the intercept due to variability between C-PODs (C-POD ID as random factor).

\begin{tabular}{cccccc}
\hline Parameter & Estimate & SE & Statistic $(z)$ & $p$-Value & OR \\
\hline Intercept & -3.173 & 0.225 & -14.111 & $<0.001$ & 0.042 \\
Season & & & & & \\
Spring & 0.081 & 0.096 & 0.844 & 0.399 & 1.085 \\
Summer & 0.029 & 0.078 & 0.369 & 0.712 & 1.029 \\
Winter & 0.407 & 0.082 & 4.99 & $<0.001$ & 1.503 \\
Diel Phase & & & & & \\
Evening & 0.435 & 0.078 & 5.557 & $<0.001$ & 1.546 \\
Morning & 0.391 & 0.084 & 4.63 & $<0.001$ & 1.479 \\
$\quad$ Night & 0.196 & 0.068 & 2.879 & 0.004 & 1.217 \\
Tidal Cycle & & & & & \\
Flood & -0.03 & 0.059 & -0.504 & 0.614 & 0.971 \\
Slack High & 0.224 & 0.049 & 4.591 & $<0.001$ & 1.252 \\
Slack Low & -0.338 & 0.057 & -5.953 & $<0.001$ & 0.713 \\
Tidal Phase & & & & & 0.812 \\
Spring Tide & -0.209 & 0.064 & -3.259 & 0.001 & 0.91 \\
Trans. Phase & -0.095 & 0.055 & -1.723 & 0.085 & \\
$\Sigma^{2}$ (intercept) & 0.512 & & & &
\end{tabular}

Winter is the season with the highest predicted foraging at Moneypoint (Figure 5a), significantly higher than the other seasons. The differences in foraging between autumn, spring and summer are not statistically significant according to the model (Table 2). The LR test for season revealed that the overall effect on foraging of this variable was statistically significant $\left(X^{2}(3)=41.42, p<0.001\right)$. Looking at the tidal cycle (Figure $5 b$ ), ebb and flood have similar foraging predictions, while slack high and slack low tides have significantly higher and lower odds of detecting foraging trains, respectively (Table 2). The differences in predicted foraging across tidal phases were relatively small (Figure $5 \mathrm{c}$ ), with spring tides predicting significantly lower foraging compared to neap tides and transitional phases (Table 2). Finally, mornings and evenings predicted the highest foraging for the diel phases, followed by night (Figure 5d). Daytime predicted significantly lower foraging (Table 2). LR tests for diel phase $\left(\mathrm{X}^{2}(3)=41.23, p<0.001\right)$, tidal cycle $\left(\mathrm{X}^{2}(3)=103.15, p<0.001\right)$ and tidal 
phase $\left(X^{2}(2)=11.13, p<0.01\right)$ confirmed that the overall effect on foraging is significant for each variable.

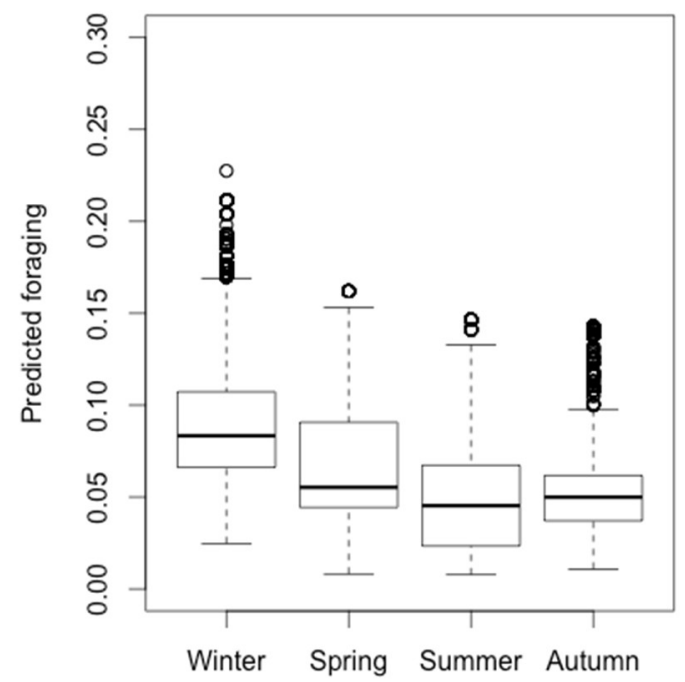

(a)

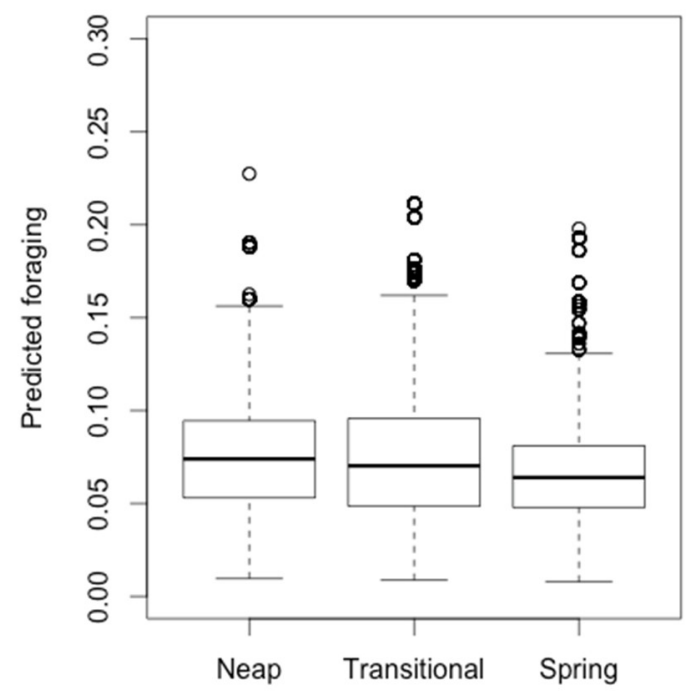

(c)

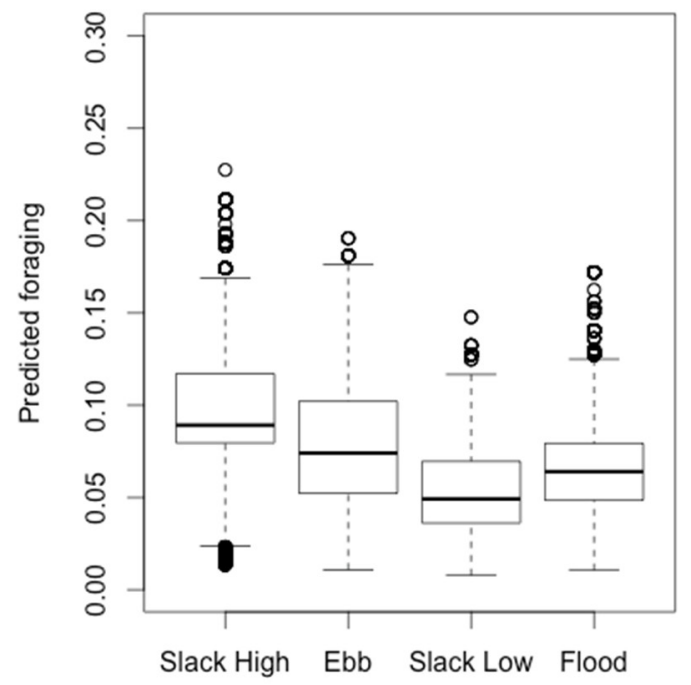

(b)

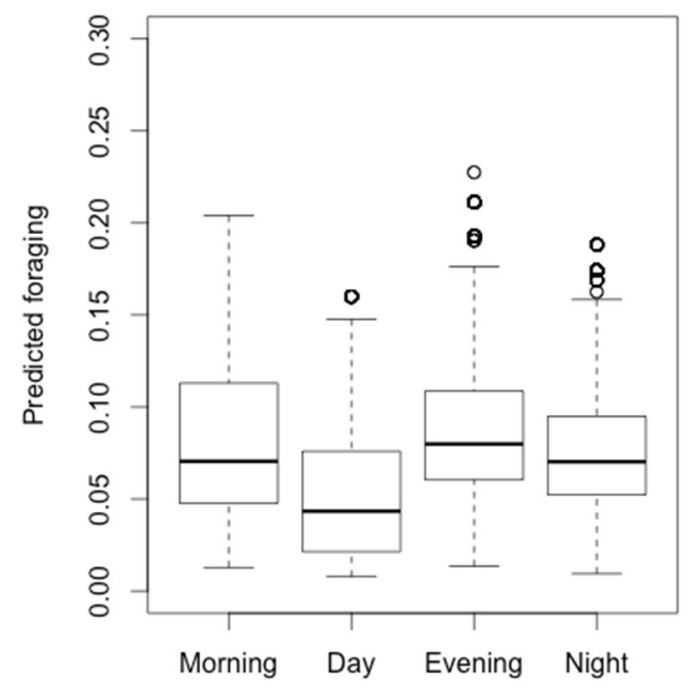

(d)

Figure 5. Predicted foraging at Moneypoint for the explanatory variables included in the best model: (a) Season; (b) Tidal Cycle; (c) Tidal Phase and (d) Diel Phase.

\subsection{Foynes}

C-PODs were deployed off Foynes Island for a total of 1428 days between February 2009 and November 2014. A total of 16,445 bottlenose dolphin click trains were recorded on 549 different days, i.e., $38.4 \%$ of days monitored (Figure 3). A total of 2538 click trains (15.4\% of total) were classified as foraging trains (Figure 4). At this location, just like observed for Moneypoint, a high proportion of all click trains, namely $64 \%$, were recorded at night.

The stepwise model selection to describe the observed foraging for Foynes (Table A2), starting with the single variable season, also resulted in a final model included all four variables (Table 3) and predicted foraging is presented as boxplots in Figure 6. Loglikelihood Ratio tests for season $\left(X^{2}(3)=272.97, p<0.001\right)$, tidal cycle $\left(X^{2}(3)=26.20, p<0.001\right)$, tidal phase $\left(X^{2}(2)=269.76, p<0.001\right)$ and diel phase $\left(X^{2}(3)=76.06, p<0.001\right)$ indicated that, just like for Moneypoint, the overall effect of every variable included in the model is significant. However, there are clear differences in model estimates and predicted foraging 
across the levels of these variables between the study locations. Autumn had the highest predicted foraging at Foynes and all other seasons had significantly lower odds of detecting foraging trains and thus lower predicted foraging (Table 3; Figure 6a). The differences in predicted foraging between ebb, flood, slack high and slack low are rather small, with flood tides having the lowest (Figure 6b). Foraging differences across the tidal phases were more distinct at Foynes compared to Moneypoint (Figure 6c), with spring tides predicting significantly higher foraging than neap tides and transitional phases (Table 3). Finally, evenings have the highest significant odds of detecting foraging trains, followed by nights (Table 3). These differences between the diel phases are visible in the predicted foraging boxplots as well (Figure 6d).

\subsection{Aughinish}

SAM was carried out for a total of 812 days between November 2011 and November 2014 at Aughinish. A total of 3471 click trains were detected on 165 different days accounting for $20.3 \%$ of days monitored (Figure 3 ), with 437 click trains (12.6\% of total) classified as foraging trains at this site (Figure 4). Further, an impressive $85 \%$ of all trains were recorded during nighttime.

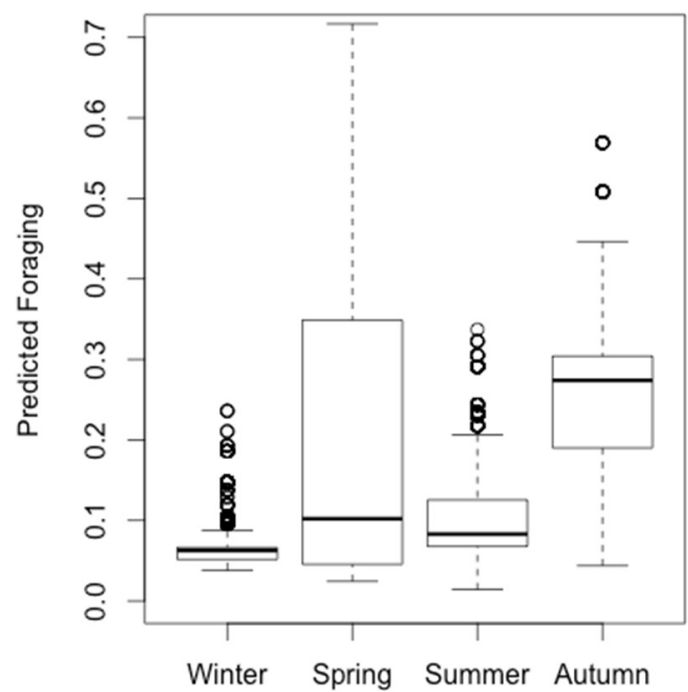

(a)

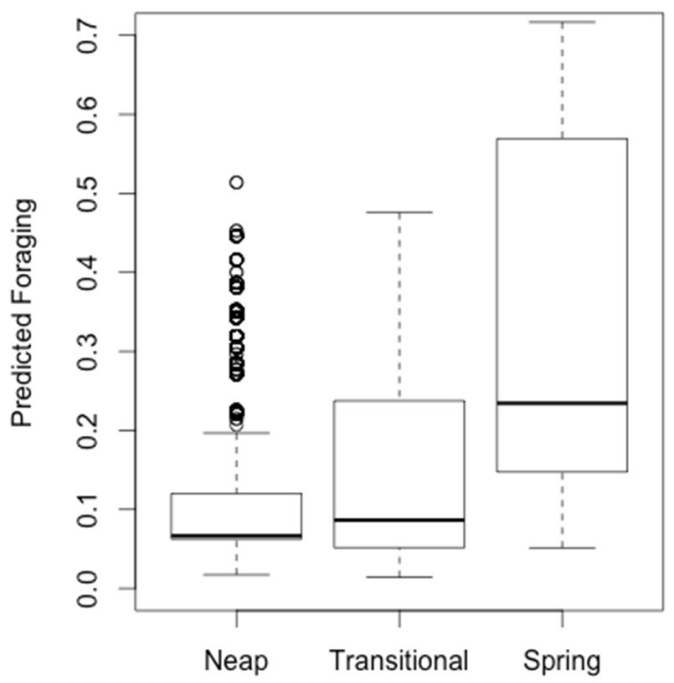

(c)

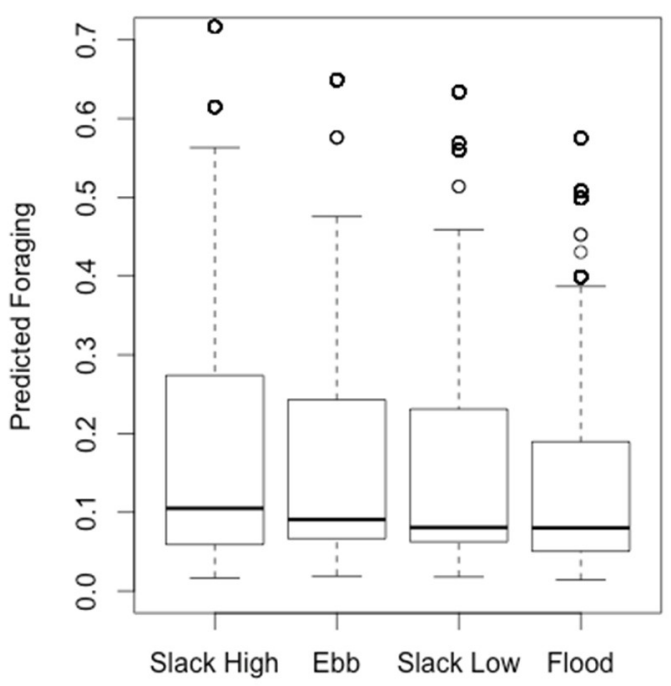

(b)

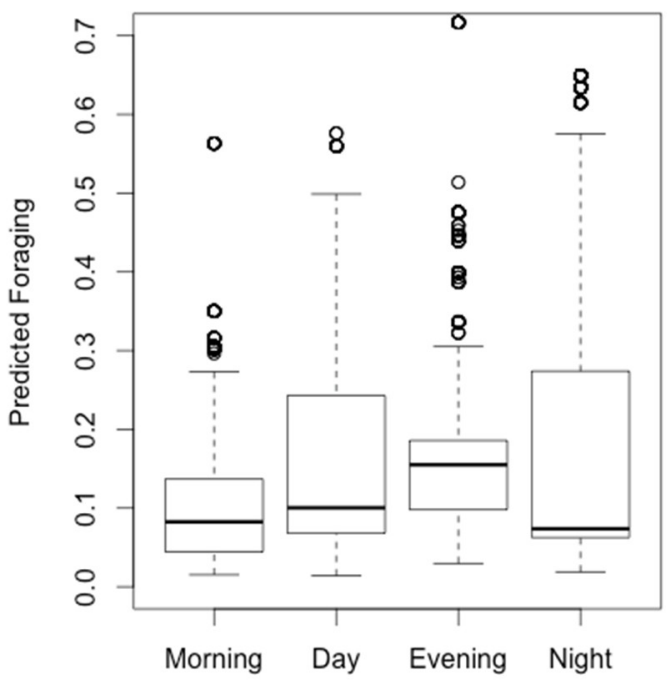

(d)

Figure 6. Predicted foraging at Foynes for the explanatory variables included in the best model: (a) Season; (b) Tidal Cycle; (c) Tidal Phase and (d) Diel Phase. 
Table 3. Final model for Foynes ( $n=16,445$ minICIs of which 2538 classified as foraging. Recorded by 9 different C-POD units). Estimates with standard errors (SE) and odds ratios (OR) of the variables included in the model. $\Sigma^{2}$ is the variance of the intercept due to variability between C-PODs (C-POD ID as random factor).

\begin{tabular}{cccccc}
\hline Parameter & Estimate & SE & Statistic $(z)$ & $p$-Value & OR \\
\hline Intercept & -1.636 & 0.301 & -5.44 & $<0.001$ & 0.195 \\
Season & & & & & \\
Spring & -0.905 & 0.116 & -7.832 & $<0.001$ & 0.404 \\
Summer & -1.168 & 0.075 & -15.605 & $<0.001$ & 0.311 \\
Winter & -0.721 & 0.154 & -4.669 & $<0.001$ & 0.486 \\
Diel Phase & & & & & \\
Evening & 0.768 & 0.091 & 8.438 & $<0.001$ & 2.156 \\
Morning & 0.095 & 0.103 & 0.916 & 0.36 & 1.099 \\
Night & 0.308 & 0.069 & 4.482 & $<0.001$ & 1.361 \\
Tidal Cycle & & & & & \\
Flood & -0.311 & 0.064 & -4.895 & $<0.001$ & 0.732 \\
Slack High & -0.147 & 0.07 & -2.088 & 0.037 & 0.863 \\
Slack Low & -0.066 & 0.066 & -1.007 & 0.314 & 0.936 \\
Tidal Phase & & & & & \\
Spring Tide & 0.954 & 0.079 & 12.075 & $<0.001$ & 2.596 \\
Trans. Phase & -0.219 & 0.057 & -3.831 & $<0.001$ & 0.803 \\
$\Sigma^{2}$ (intercept) & 0.707 & & & & \\
\hline
\end{tabular}

The best model for the foraging behavior at Aughinish included, just like for Moneypoint and Foynes, all four explanatory variables (Table A3; Table 4). The overall effect of every single variable was statistically significant according to their respective LR tests (season: $X^{2}(3)=39.01, p<0.001$; diel phase: $X^{2}(3)=19.45, p<0.001$; tidal cycle: $X^{2}(3)=34.76, p<0.001$ and tidal phase: $\left.X^{2}(2)=6.17, p<0.05\right)$. Just like for Foynes, autumn has the highest predicted foraging of all seasons (Figure 7a). Ebbing tides are predictors of the highest foraging for the tidal cycle and flood, slack low and slack high all have significantly lower odds of detecting foraging trains, which is reflected by the predictions (Table 4; Figure 7b). Further, predicted foraging is highest for neap tides of the tidal phase (Figure 7c) and at nighttime (Figure 7d). The foraging across the levels of the variables shows clear differences compared to the findings for Moneypoint and Foynes.

Table 4. Final model for Aughinish ( $n=3471$ minICIs of which 437 classified as foraging. Recorded by 6 different C-POD units). Estimates with standard errors (SE) and odds ratios (OR) of the variables included in the model. $\Sigma^{2}$ is the variance of the intercept due to variability between C-PODs (C-POD ID as random factor).

\begin{tabular}{|c|c|c|c|c|c|}
\hline Parameter & Estimate & SE & Statistic $(z)$ & $p$-Value & OR \\
\hline Intercept & -1.091 & 0.49 & -2.227 & 0.026 & 0.336 \\
\hline \multicolumn{6}{|l|}{ Season } \\
\hline Spring & -1.268 & 0.371 & -3.421 & $<0.001$ & 0.281 \\
\hline Summer & -1.178 & 0.237 & -4.968 & $<0.001$ & 0.308 \\
\hline Winter & -1.65 & 0.375 & -4.398 & $<0.001$ & 0.192 \\
\hline \multicolumn{6}{|l|}{ Diel Phase } \\
\hline Evening & 0.217 & 0.434 & 0.499 & 0.618 & 1.242 \\
\hline Morning & -0.902 & 0.607 & -1.486 & 0.134 & 0.406 \\
\hline Night & 0.692 & 0.4 & 1.739 & 0.082 & 1.999 \\
\hline \multicolumn{6}{|l|}{ Tidal Cycle } \\
\hline Flood & -0.406 & 0.177 & -2.289 & 0.022 & 0.666 \\
\hline Slack High & -1.168 & 0.213 & -5.474 & $<0.001$ & 0.311 \\
\hline Slack Low & -0.443 & 0.137 & -3.227 & 0.001 & 0.642 \\
\hline \multicolumn{6}{|l|}{ Tidal Phase } \\
\hline Spring Tide & 0.524 & 0.211 & 2.481 & 0.013 & 1.689 \\
\hline Trans. Phase & 0.091 & 0.144 & 0.63 & 0.529 & 1.095 \\
\hline$\Sigma^{2}$ (intercept) & 0.141 & & & & \\
\hline
\end{tabular}




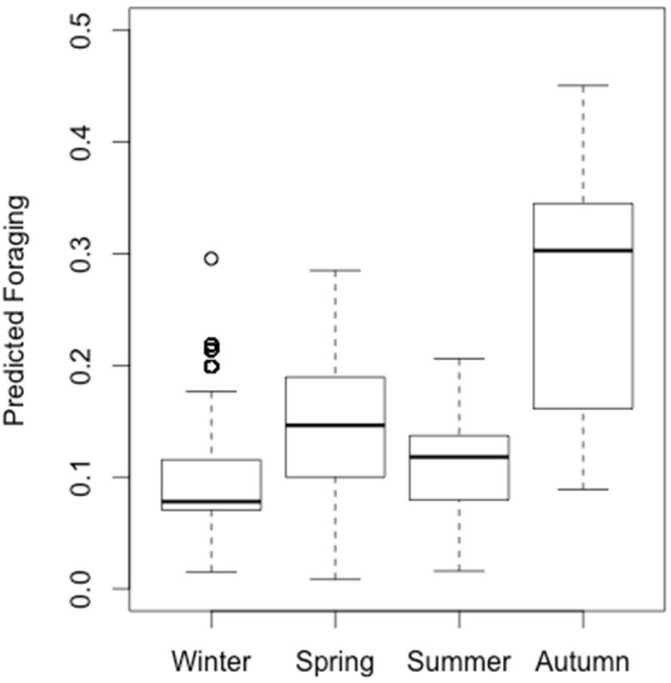

(a)

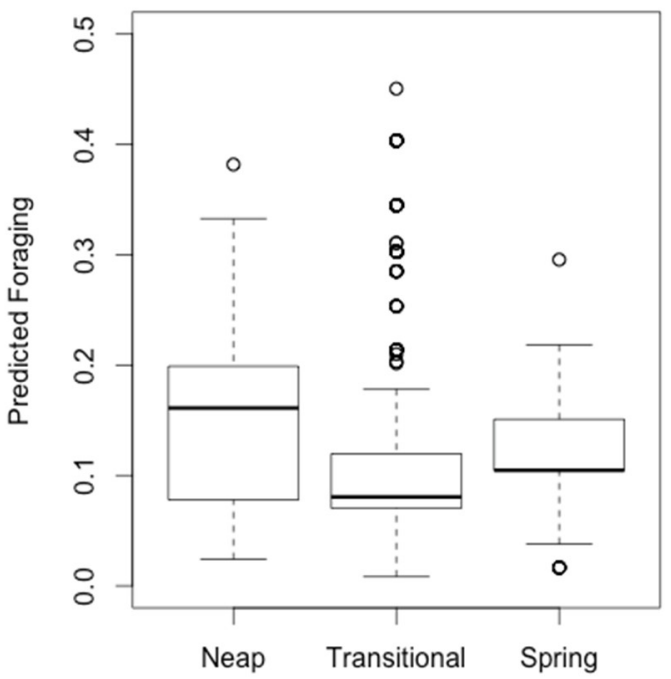

(c)

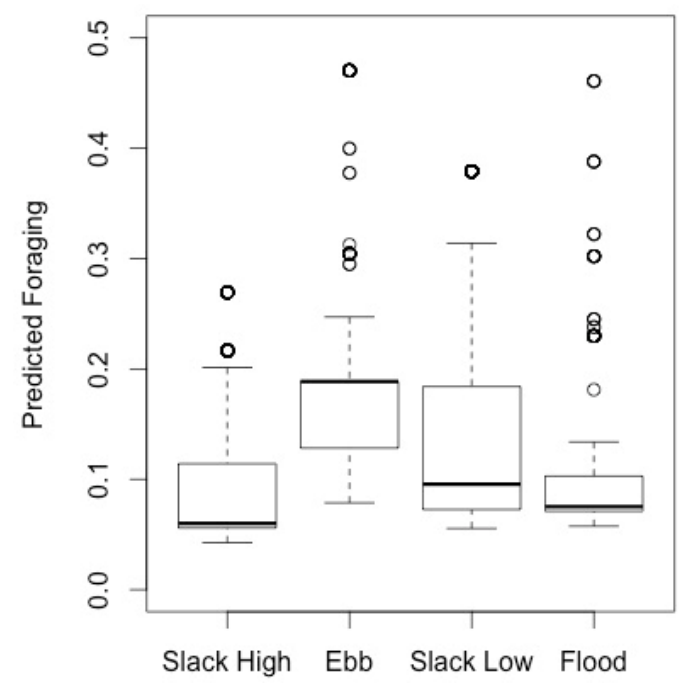

(b)

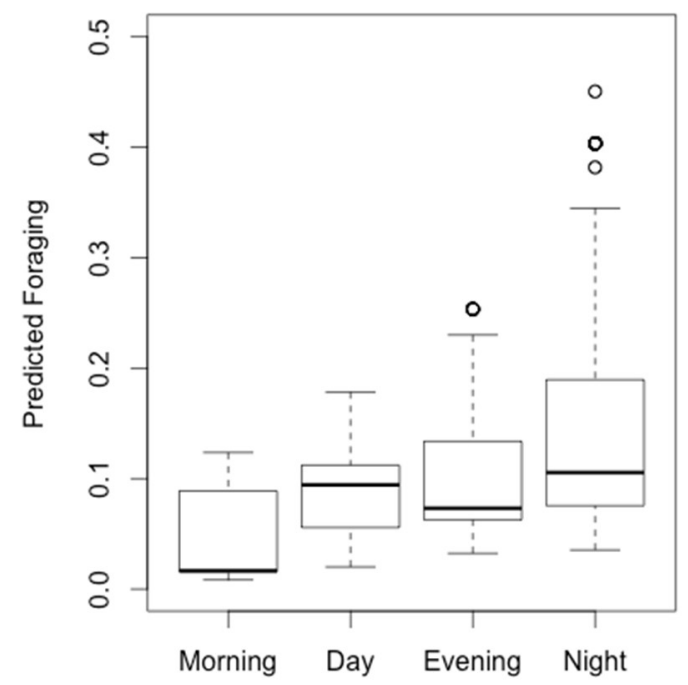

(d)

Figure 7. Predicted foraging at Aughinish for the explanatory variables included in the best model: (a) Season; (b) Tidal Cycle, (c) Tidal Phase and (d) Diel Phase.

\subsection{Shannon Airport}

Between November 2011 and December 2013, C-PODs were deployed for a total of 738 days at Shannon Airport, resulting in the detection of 8184 click trains on 117 different days, i.e., $15.9 \%$ of days monitored (Figure 3). A total of 1792 trains $(21.9 \%$ of total) were classified as foraging (Figure 4).

Shannon Airport was the only location where the best model did not include all four variables. Starting with tidal cycle, only adding the tidal phase resulted in a significantly better model (Table A4). Hence, only the tidal variables were included in the final model for Shannon Airport (Table 5), indicating that at this location further inland, the tides predominantly affect the foraging behavior of the dolphins. Time of day and season are less important at Shannon Airport, which is in contrast with the findings for the other study locations. Flooding tides have the lowest predicted foraging (Figure 8a), while the predictions do not seem to differ substantially between the tidal phases (Figure $8 b$ ). The overall effects on foraging of both tidal cycle $\left(\mathrm{X}^{2}(3)=22.81, p<0.001\right)$ and tidal phase $\left(X^{2}(2)=6.61, p<0.05\right)$ were statistically significant according to the LR tests. 
Table 5. Final model for Shannon Airport ( $n=8184$ minICIs of which 1792 classified as foraging. Recorded by 6 different C-POD units). Estimates with standard errors (SE) and odds ratios (OR) of the variables included in the model. $\Sigma^{2}$ is the variance of the intercept due to variability between C-PODs (C-POD ID as random factor).

\begin{tabular}{cccccc}
\hline Parameter & Estimate & SE & Statistic $(z)$ & $p$-Value & OR \\
\hline Intercept & -1.308 & 0.24 & -5.441 & $<0.001$ & 0.27 \\
Tidal Cycle & & & & & \\
Flood & -0.329 & 0.071 & -4.623 & $<0.001$ & 0.719 \\
Slack High & -0.108 & 0.071 & -1.52 & 0.128 & 0.898 \\
Slack Low & -0.244 & 0.14 & -1.75 & 0.08 & 0.783 \\
Tidal Phase & & & & & \\
Spring Tide & -0.15 & 0.092 & -1.626 & 0.104 & 0.861 \\
Trans. Phase & -0.157 & 0.063 & -2.489 & 0.013 & 0.854 \\
$\Sigma^{2}$ (intercept) & 0.284 & & & & \\
\hline
\end{tabular}

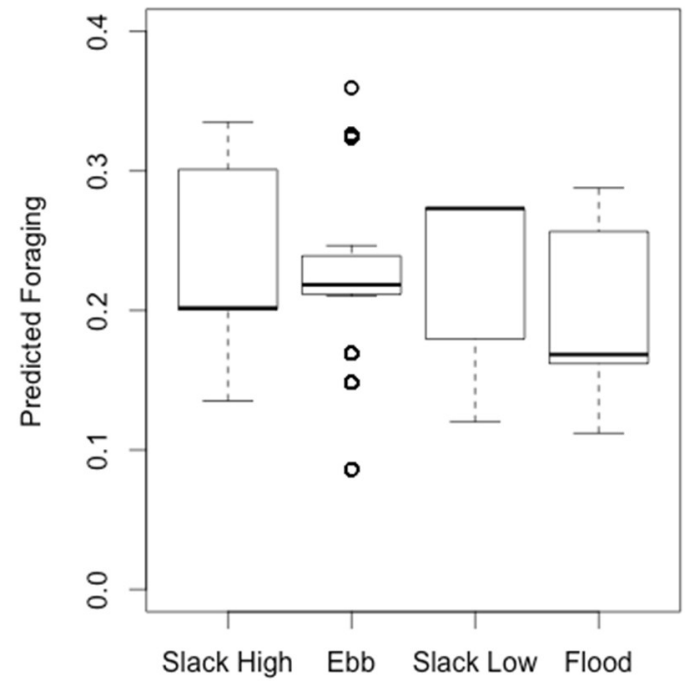

(a)

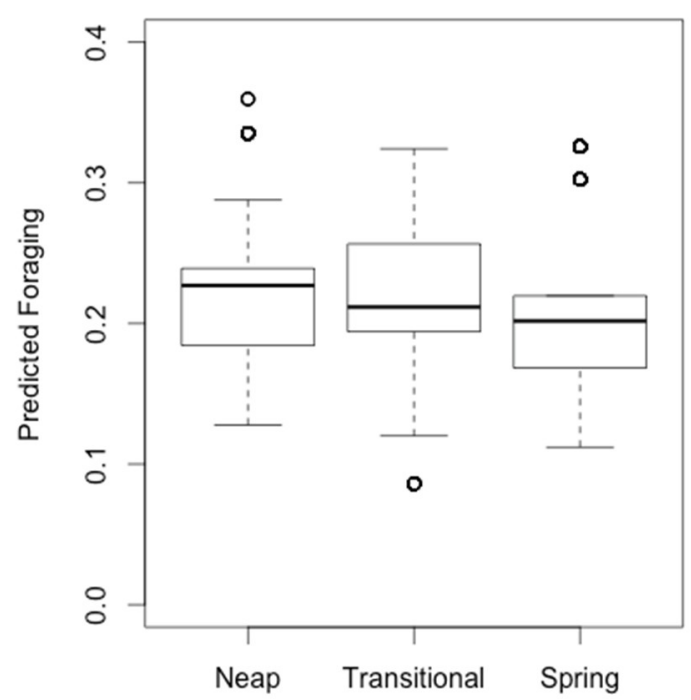

(b)

Figure 8. Predicted foraging at Shannon Airport for the explanatory variables included in the best model: (a) Tidal Cycle and (b) Tidal Phase.

\section{Discussion}

The present study was the first attempt to understand dolphin presence and their foraging behavior throughout the year across various locations in the middle and inner Shannon Estuary. Dolphin presence was found to decrease with increased distance from the estuary mouth while foraging was found to be considerably higher in the upriver area. Modeled relationships and predictions for seasonal, tidal and diel foraging were highly variable across the study locations, indicating that changes in dolphin behavior occurred over relatively small geographical scales.

The main objective of this study was to explore the foraging behavior of dolphins at deep-water berths, but the data also provided information on the presence of dolphins at these different locations. Previously studies have shown dolphins present on $73 \%$ days at Moneypoint and $41 \%$ at Foynes [29]. The present study showed similar detection rates, with $71 \%$ of days at Moneypoint with dolphin detections and 38\% at Foynes. Dolphin presence was detected on $20 \%$ and $16 \%$ of the days monitored at Aughinish and Shannon Airport, indicating that the presence of dolphins decreases with increased distance from the estuary mouth. However, these relatively high detection rates high up in the inner estuary highlights that these sites are frequently used by dolphins, which was previously unknown. It was also evident that dolphins were detected during all seasons at all locations, 
supporting the year round residency pattern of the dolphins within the estuary, or at least part of the population given that SAM is unable to provide abundance estimations [29]. Although the number of individual dolphins present at the study locations throughout the year was largely unknown, group sizes recorded visually are typically between 5 and 12 individuals with a mean group size of 9.7 dolphins [18].

The use of GLMM was deemed appropriate for this study including the different C-POD units as a random factor. The variances of the intercept estimates for every model confirmed differences between C-PODs that needed to be accounted for. The stepwise model selection procedure in order to identify the model that best fitted the binomial response variable was deemed a good approach yielding interesting predictions across the levels of the four explanatory variables.

\subsection{Foraging}

Although Moneypoint had the highest dolphin presence, dolphins spent less time foraging at this site, with only slightly over $7 \%$ of all trains classified as foraging. Foraging at Foynes, Aughinish and Shannon Airport ranged from over 12\% to almost 22\%, which is considerably higher than Moneypoint. The importance of these sites for foraging is underlined when you consider dolphin presence was only detected on between $15.9 \%$ and $38.4 \%$ of days monitored. This higher foraging activity in areas less frequented by the dolphins is the opposite reported from the Moray Firth, Scotland, where feeding behavior during the day was significantly higher at sites intensively used by this resident bottlenose dolphin population [26].

The differences in foraging between the middle and inner areas of the Shannon Estuary may be due to differences in habitat availability and use, as suggested for Cardigan Bay, Wales, where another resident population of bottlenose dolphins has been studied [37]. Here, northern areas of the bay are assumed to be more important for mating and socializing while feeding and nursing predominately occurred in the southern areas of Cardigan Bay [37].

The present study found lower presence but higher foraging upriver, suggesting that foraging is an important stimulus for dolphins to travel upriver, while the high presence but lower foraging at Moneypoint suggests this area is not necessarily used for foraging but mainly for other activities, for example, socializing. Moneypoint had previously been identified, along with an area at the estuary mouth, as one of two critically important habitats for this population also for foraging $[7,13]$; however, no sites had been surveyed in the inner estuary. Our study suggests although important for foraging, there are other more important sites, not previously identified. The use of the inner estuary as a significant foraging area is an important contribution to our understanding of the dolphins' use of the estuary. Further, the potential expansion of industrial activity and port facilities within the estuary is concentrated within the inner estuary [8] and could have a negative impact on the dolphins if it was to disturb them in these areas. However, this study was carried out at active deep-water berths suggesting the presence of ships is not a significant deterrent to dolphin presence but this should be explored in more detail.

\subsection{Seasonal Foraging}

Habitat use by bottlenose dolphins is greatly dependent upon food availability and the presence/absence of predators [38]. The absence of large predators in the Shannon Estuary suggests that seasonal differences in foraging across locations are mainly in response to prey availability and distribution $[3,18,39]$. Seasonal variation in dolphin sightings in the Moray Firth, Scotland, were linked to seasonal migrations of adult salmonids in spring and summer [40] and increased observations of feeding/foraging in Cardigan Bay has also been shown to coincide with periods of high prey richness [41].

Bottlenose dolphins are generalist and opportunistic feeders, i.e., they forage intensively when prey is abundant, and on a wide variety of fish [24,25]. Foraging was predicted to be the highest in winter at Moneypoint, followed by spring, which was also the second 
most important season for Foynes and Aughinish. This higher foraging during spring could be correlated with the onset of the migration of Atlantic Salmon (Salmo salar) into the estuary $[3,18,42]$. Low foraging in autumn was attributed to the lower presence of dolphins at Moneypoint [29] and the lower abundance of salmon [3,42]. The highest proportion of time spent foraging was reported during autumn at Foynes and Aughinish (median c. 30\%). Other seasons were considerably less important, but still had predicted foraging times close to the maximum reported at Moneypoint. This finding suggests that the Shannon dolphins allocated more time to foraging when they occurred upriver, suggesting these areas are foraging hotspots. It is likely that the high foraging rates can be attributed to high prey abundances [39], and low presence and foraging at Moneypoint suggests that dolphins move upriver during autumn, presumably to forage on abundant and/or more available prey [18]. Furthermore, lower detection rates in the inner estuary indicate that dolphins do not often travel upriver, but when they do it is mainly for foraging. This knowledge on seasonal variation in foraging across locations can be used to inform planning. Informed decisions should be made on a site-by-site basis given the level of partitioning in habitat use across sites. The timing of increased industrial activity in the estuary should be carried out in consultation with long-term monitoring to ensure important areas are not made unavailable to dolphins at critical periods in the year.

\subsection{Tidal Foraging}

The Shannon Estuary has a strong tidal character with vertical tidal ranges up to $5 \mathrm{~m}$ during spring tide events [7] and these characteristics are likely to affect the foraging behavior of bottlenose dolphins. Generally, tidal flow has an effect on water salinity and temperature and is known to create upwelling zones, haloclines and tidal fronts, which influences the abundance and movements of potential dolphin prey $[3,26,39,43]$. Further, foraging in tidal currents increases the chances of prey encounters and offers, whether or not in combination with steep benthic slopes that concentrate prey, favorable conditions for foraging $[3,7,43,44]$. Such use of currents in deep-water channels has been documented for bottlenose dolphins in the Moray Firth and harbor porpoises in Ramsey Sound, Wales [43,44]. Fortnightly tidal variations, i.e., the tidal phases, are changes in average daily tidal height and result in stronger and weaker tidal currents during spring and neap phases, respectively [45]. Such variations were not correlated to foraging, but higher tidal current velocity might enhance the benefits from foraging during flowing tides, i.e., maximizing prey encounters. Visual surveys in the past have shown that the Shannon dolphins are more likely to be foraging during flowing tides, i.e., ebb and flood, and ebbing tides in particular [7], with foraging reaching its maximum during mid-ebb and mid-flood periods when tidal currents are at their strongest [27]. The present study shows that foraging is related to the tidal phase and cycle but can be highly variable across locations, although ebb tides were predictors of high foraging at all sites except Shannon Airport. The observed differences in tidal foraging may be attributed to different environmental characteristics or prey type and, hence, the use of different foraging techniques to optimize foraging at each location.

\subsection{Diel Foraging}

Diel variations in foraging by bottlenose dolphins are expected to be related to shortterm prey abundances and the environmental characteristics of their habitat [46]. Crepuscular foraging, i.e., foraging during morning and evening hours, was observed for bottlenose dolphin populations on the pacific coast of the U.S. and in the Gulf of Mexico [46,47]. In the Sado Estuary (Portugal) and New Quay Bay (Wales), dolphins were found to actively forage during morning hours $[19,48]$. Results from the present study indicate that the dolphins in the Shannon have crepuscular foraging patterns at Moneypoint, with mornings and evenings predicting the highest foraging, while at Foynes only evenings had the highest foraging. These findings might be associated with either nocturnal or diurnal activity of prey species, which makes them more susceptible to predation during their transitional 
periods, essentially mornings and/or evenings. Further, foraging was predicted to be lower at night, although the dolphins were acoustically more active at night, with $63 \%$ of all trains recorded during nighttime. Studies that were able to assess nightly foraging of bottlenose dolphins found higher foraging activity at night $[49,50]$, which is in contrast with our results for the Shannon population. Knowledge on nocturnal activity and foraging can be used to inform mitigation requirements during developments.

\subsection{Implications for Management and Conservation}

The Shannon Estuary is an important industrial area and, at the same time, one of the most important habitats for bottlenose dolphins in Ireland. It is designated as a SAC under the EU Habitats Directive, which means that it should be managed according to the ecological needs of the dolphins [4]. The SIFP for the Shannon Estuary supports expansion of the existing economic base and port/harbor facilities while maintaining the estuary's ecological integrity and biodiversity [8]. The present study provides valuable information to address knowledge gaps on the ecology and behavior of the bottlenose dolphins in order to achieve effective conservation of this SAC. The SIFP states that the region of the Shannon Estuary has valuable resources with a significant unrealized potential, which is intended to be exploited in the future [8]. Moneypoint, as well as several locations close to Foynes and Aughinish, are presented as strategic development locations under the SIFP [8]. Increased industrial activity and expansion of port facilities might introduce new, or aggravate existing pressures, on the dolphins, such as increased shipping activity and noise pollution, which are thought to affect their behavior [51-53]. If these threats are significant or predominate for a significant amount of time, it could potentially impact on resident individuals using these areas if proper mitigation is not administered from the onset.

\section{Conclusions}

This study revealed that foraging across seasons, tidal phase, tidal cycle and diel phase is very variable between locations, indicating that foraging behavior of bottlenose dolphins can vary on relatively small geographical scales, thus indicating the dynamic nature of the Shannon Estuary. This implies that conservation efforts should not only consider the estuary as a whole, but as an aggregation of several dynamic habitats with large differences in the presence and foraging activity of the dolphins. Future development initiatives in the inner estuary should take into account these results in order to mitigate disturbance to the dolphins during important foraging periods on a daily and seasonal basis. Further, the high foraging combined with relatively low presence of dolphins in the inner estuary suggests that the assumed abundance of prey is an important stimulus for the dolphins to travel upriver, and these areas should be considered foraging hotspots.

SAM using C-PODs has proven to be a very valuable tool to investigate the echolocation behavior of the bottlenose dolphins in the Shannon Estuary. Their proposed applications in investigating long-term patterns in foraging behavior and identifying important feeding areas have been identified by this study. Further, they were able to provide an insight in nocturnal echolocation activity and foraging of this dolphin population. Overall, the results of the present study can be considered a baseline of the presence and foraging behavior of the bottlenose dolphins in the Shannon Estuary and will aid in the proper conservation of this resident population. Future studies, both visual surveys and longterm acoustic monitoring, are necessary to fully understand the ecology, behavior and distribution of this exceptional population.

Author Contributions: Conceptualization, J.M.O. and S.D.B.; methodology, J.M.O. and S.D.B.; software, M.C.; validation, M.C. and J.M.O.; formal analysis, M.C.; investigation, M.C. and J.M.O.; resources, S.D.B. and J.M.O.; data curation, S.D.B. and J.M.O.; writing—original draft preparation, M.C.; writing—review and editing, All; visualization, M.C.; supervision, J.M.O.; project administration, S.D.B. and J.M.O.; funding acquisition, S.D.B. and J.M.O. All authors have read and agreed to the published version of the manuscript. 
Funding: This research was funded by a number of agencies, including the EPA through a Small Study Grant, the Irish Whale and Dolphin Group, the Strategic Integrated Framework Plan (SIFP) for the Shannon Estuary, and the Marine Institute under a project entitled Marine Mammals and Megafauna in Irish Waters, behavior, distribution and habitat use Marine Research Sub-program 2007-2013 (NDP 2007-2013) (PBA/ME/07/005(02).

Institutional Review Board Statement: Not applicable.

Informed Consent Statement: Not applicable.

Data Availability Statement: The data presented in this study are available on request from the corresponding author. The data are not publicly available, as it is owned by various organizations.

Acknowledgments: We would like to thank Tara Higgins and Tadhg O'Mahony of the EPA and Sheila Downes of Clare County Council/SIFP for their support. Hugh Conlon of Shannon Foynes Port Company, Sinéad Ryan of Aughinish Alumina and John Wall of Moneypoint Power Station allowed us to deploy CPODs from their jetties.

Conflicts of Interest: The authors declare no conflict of interest.

\section{Appendix A}

Table A1. Stepwise model selection for Moneypoint. $X^{2}$-tests are between the multivariable model and the model with one variable less, i.e., the last one in the formula. (Formula: For = foraging (response variable), $\mathrm{Tc}=$ tidal cycle, $\mathrm{D}=$ diel phase, $\mathrm{S}=$ season, $\mathrm{T} p=$ tidal phase, $\mathrm{ID}=\mathrm{C}-\mathrm{POD}$ ID (random variable).

\begin{tabular}{|c|c|c|c|}
\hline & Formula & AIC & $X^{2}$-Test \\
\hline \multirow{4}{*}{$\begin{array}{l}\text { Single Variable } \\
\text { Models }\end{array}$} & For $\sim S+(1 \mid$ ID $)$ & 21830 & $\mathrm{~N} / \mathrm{A}$ \\
\hline & For $\sim \mathrm{Tp}+(1 \mid \mathrm{ID})$ & 21870 & $\mathrm{~N} / \mathrm{A}$ \\
\hline & For $\sim$ Tc $+(1 \mid \mathrm{ID})$ & 21762 & $\mathrm{~N} / \mathrm{A}$ \\
\hline & For $\sim \mathrm{D}+(1 \mid \mathrm{ID})$ & 21827 & $\mathrm{~N} / \mathrm{A}$ \\
\hline \multirow{3}{*}{ Stepwise Models } & For $\sim \mathrm{Tc}+\mathrm{D}+(1 \mid \mathrm{ID})$ & 21726 & $X^{2}(3)=41.03, p<0.001$ \\
\hline & For $\sim \mathrm{Tc}+\mathrm{D}+\mathrm{S}+(1 \mid \mathrm{ID})$ & 21696 & $X^{2}(3)=36.00, p<0.001$ \\
\hline & For $\sim \mathrm{Tc}+\mathrm{D}+\mathrm{S}+\mathrm{Tp}+(1 \mid \mathrm{ID})$ & 21689 & $X^{2}(2)=11.13, p<0.01$ \\
\hline
\end{tabular}

Table A2. Stepwise model selection for Foynes. Details see Table A1.

\begin{tabular}{|c|c|c|c|}
\hline & Formula & AIC & $X^{2}$-Test \\
\hline & For $\sim S+(1 \mid \mathrm{ID})$ & 12496 & $\mathrm{~N} / \mathrm{A}$ \\
\hline Single Variable & For $\sim \mathrm{Tp}+(1 \mid \mathrm{ID})$ & 12522 & $\mathrm{~N} / \mathrm{A}$ \\
\hline \multirow{3}{*}{ Models } & For $\sim$ Tc + (1। ID) & 12694 & $\mathrm{~N} / \mathrm{A}$ \\
\hline & For $\sim \mathrm{D}+(1 \mid \mathrm{ID})$ & 12669 & $\mathrm{~N} / \mathrm{A}$ \\
\hline & For $\sim \mathrm{S}+\mathrm{Tp}+(1 \mid \mathrm{ID})$ & 12239 & $X^{2}(2)=260.16, p<0.001$ \\
\hline \multirow[t]{2}{*}{ Stepwise Models } & For $\sim \mathrm{S}+\mathrm{Tp}+\mathrm{D}+(1 \mid \mathrm{ID})$ & 12172 & $X^{2}(3)=73.55, p<0.001$ \\
\hline & For $\sim \mathrm{S}+\mathrm{Tp}+\mathrm{D}+\mathrm{T} \mathrm{c}+(1 \mid \mathrm{ID})$ & 12152 & $X^{2}(2)=26.20, p<0.001$ \\
\hline
\end{tabular}

Table A3. Stepwise model selection for Aughinish. Details see Table A1.

\begin{tabular}{|c|c|c|c|}
\hline & Formula & AIC & $X^{2}$-Test \\
\hline & For $\sim S+(1 \mid$ ID $)$ & 2545 & $\mathrm{~N} / \mathrm{A}$ \\
\hline Single Variable & For $\sim \mathrm{Tp}+(1 \mid \mathrm{ID})$ & 2569 & $\mathrm{~N} / \mathrm{A}$ \\
\hline \multirow[t]{3}{*}{ Models } & For $\sim \mathrm{Tc}+(1 \mid \mathrm{ID})$ & 2550 & $\mathrm{~N} / \mathrm{A}$ \\
\hline & For $\sim \mathrm{D}+(1 \mid \mathrm{ID})$ & 2548 & $\mathrm{~N} / \mathrm{A}$ \\
\hline & For $\sim \mathrm{S}+\mathrm{D}+(1 \mid \mathrm{ID})$ & 2528 & $X^{2}(3)=22.55, p<0.001$ \\
\hline \multirow[t]{2}{*}{ Stepwise Models } & For $\sim \mathrm{S}+\mathrm{D}+\mathrm{TC}+(1 \mid \mathrm{ID})$ & 2501 & $X^{2}(3)=32.74, p<0.001$ \\
\hline & For $\sim \mathrm{S}+\mathrm{D}+\mathrm{Tc}+\mathrm{Tp}+(1 \mid \mathrm{ID})$ & 2499 & $X^{2}(2)=6.17, p<0.05$ \\
\hline
\end{tabular}


Table A4. Stepwise model selection for Shannon Airport. Details see Table A1.

\begin{tabular}{|c|c|c|c|}
\hline & Formula & AIC & $\mathrm{X}^{2}$-Test \\
\hline \multirow{4}{*}{$\begin{array}{l}\text { Single Variable } \\
\text { Models }\end{array}$} & For $\sim S+(1 \mid$ ID $)$ & 8511 & $\mathrm{~N} / \mathrm{A}$ \\
\hline & For $\sim \mathrm{Tp}+(1 \mid \mathrm{ID})$ & 8509 & $\mathrm{~N} / \mathrm{A}$ \\
\hline & For $\sim$ Tc $+(1 \mid \mathrm{ID})$ & 8495 & $\mathrm{~N} / \mathrm{A}$ \\
\hline & For $\sim \mathrm{D}+(1 \mid \mathrm{ID})$ & 8512 & $\mathrm{~N} / \mathrm{A}$ \\
\hline \multirow{3}{*}{ Stepwise Models } & For $\sim \mathrm{Tc}+\mathrm{Tp}+(1 \mid \mathrm{ID})$ & 8492 & $X^{2}(2)=6.61, p<0.05$ \\
\hline & For $\sim \mathrm{Tc}+\mathrm{Tp}+\mathrm{D}+(1 \mid \mathrm{ID})$ & 8491 & $X^{2}(3)=7.61, p=0.055$ \\
\hline & For $\sim \mathrm{Tc}+\mathrm{Tp}+\mathrm{D}+\mathrm{S}+(1 \mid \mathrm{ID})$ & 8590 & $\mathrm{X}^{2}(2)=6.43, p=0.092$ \\
\hline
\end{tabular}

\section{References}

1. Berrow, S. Biological diversity of cetaceans (whales, dolphins and porpoises) in Irish waters. In Marine Biodiversity in Ireland and Adjacent Waters; Nunn, J.D., Ed.; Ulster Museum: Belfast, UK, 2001; pp. 115-119.

2. Whooley, P.; Berrow, S. Bowhead whale (Balaena mysticetes Linneaus), a cetacean species new to Irish waters. Ir. Nat. J. 2019, 36, 169-171.

3. Ingram, S.N. The Ecology and Conservation of Bottlenose Dolphins in the Shannon Estuary, Ireland. Ph.D. Thesis, University College Cork, Cork, Ireland, 2000.

4. Berrow, S.; O’Brien, J.; Groth, L.; Foley, A.; Voigt, K. Abundance estimate of bottlenose dolphins (Tursiops truncatus) in the Lower River Shannon candidate special area of conservation, Ireland. Aquat. Mamm. 2012, 38, 136-144. [CrossRef]

5. Baker, I.; O’Brien, J.; McHugh, K.; Ingram, S.N.; Berrow, S. Bottlenose dolphin (Tursiops truncatus) social structure in the Shannon Estuary, Ireland, is distinguished by age- and area-related associations. Mar. Mammal Sci. 2018, 34, 458-487. [CrossRef]

6. Nykänen, M.; Dillane, E.; Englund, A.; Foote, A.D.; Ingram, S.N.; Louis, M.; Rogan, E. Quantifying dispersal between marine protected areas by a highly mobile species, the bottlenose dolphin, Tursiops truncatus. Ecol. Evol. 2018, 8, 9241-9258. [CrossRef]

7. Ingram, S.N.; Rogan, E. Identifying critical areas and habitat preferences of bottlenose dolphins, Tursiops truncatus. Mar. Ecol. Prog. Ser. 2002, 244, 247-255. [CrossRef]

8. SIFP. Strategic Integrated Framework Plan for the Shannon Estuary. 2013. Available online: http://www.shannonestuarysifp.ie/ (accessed on 26 February 2021).

9. Mirimin, L.; Miller, R.; Dillane, E.; Berrow, S.D.; Ingram, S.; Cross, T.F.; Rogan, E. Fine-scale population genetic structuring of bottlenose dolphins in Irish coastal waters. Anim. Conserv. 2011, 14, 342-353. [CrossRef]

10. Knott, M.J. Two Months in Kilkee, 2nd ed.; Clasp Press: Ennis, Ireland, 1997; p. 255.

11. Berrow, S.D.; Ryan, C. An extension to the known range of Shannon Estuary Bottlenose Dolphins (Tursiops truncatus (Montagu, 1821)). Ir. Nat. J. 2013, 32, 77-78.

12. Levesque, S.; Reusch, K.; Baker, I.; O’Brien, J.; Berrow, S. Photo-identification of bottlenose Dolphins (Tursiops truncatus) in Tralee bay and Brandon Bay, Co. Kerry: A case for SAC boundary extension. Biol. Environ. 2016, 116, 109-118.

13. Rogan, E.; Garagouni, M.; Nykänen, M.; Whitaker, A.; Ingram, S. Bottlenose dolphin survey in the Lower River Shannon SAC, 2018. In Report to the National Parks and Wildlife Service; Department of Culture, Heritage and the Gaeltacht, University College Cork: Cork, Ireland, 2018; p. 19.

14. Ingram, S.; Rogan, E. Bottlenose dolphins (Tursiops truncatus) in the Shannon Estuary and selected areas of the west-coast of Ireland. Rep. Natl. Parks Wildl. Serv. 2003, 28, 1-28.

15. Englund, A.; Ingram, S.; Rogan, E. Population status report for bottlenose dolphins using the Lower River Shannon SAC, 2006-2007. Final Rep. Natl. Parks Wildl. Serv. 2007, 1-35.

16. Englund, A.; Ingram, S.; Rogan, E. An updated population status report for bottlenose dolphins using the Lower River Shannon SAC in 2008. Final Rep. Natl. Parks Wildl. Serv. 2008, 1-34.

17. O'Brien, J.; Beck, S.; Berrow, S.D.; André, M.; van der Schaar, M.; O'Connor, I.; McKeown, E.P. The Use of Deep Water Berths and the Effect of Noise on Bottlenose Dolphins in the Shannon Estuary cSAC. In The Effects of Noise on Aquatic Life II; Springer: New York, NY, USA, 2016; pp. 775-783. [CrossRef]

18. Barker, J.; Berrow, S. Temporal and spatial variation in group size of bottlenose dolphins (Tursiops truncatus) in the Shannon Estuary, Ireland. Biol. Environ. 2016, 116B, 63-70.

19. Bond, S. The Use of T-PODs to Identify Echolocation Behavior in Bottlenose Dolphins (Tursiops truncatus) in New Quay Bay, Wales; School of Biological Sciences, University of Wales: Bangor, UK, 2006; p. 130.

20. Nuuttila, H.K.; Meier, R.; Evans, P.G.H.; Turner, J.R.; Bennell, J.D.; Hiddink, J.G. Identifying foraging behavior of wild bottlenose dolphins (Tursiops truncatus) and harbour porpoises (Phocoena phocoena) with static acoustic dataloggers. Aquat. Mamm. 2013, 39, 147-161. [CrossRef]

21. Au, W.W.L. The Sonar of Dolphins; Springer: Berlin, Germany, 1993; Volume 1. [CrossRef]

22. Benoit-Bird, K.J.; Au Whitlow, W.L. Echolocation click rates and behavior of foraging Hawaiian spinner dolphins. J. Acoust. Soc. Am. 2004, 115, 2374. [CrossRef]

23. Au, W. The sonar of dolphins. Acoust. Aust. 2004, 32, 61-63. 
24. Beddia, L. Diurnal Behavior of Bottlenose Dolphins (Tursiops truncatus) in the Cardigan Bay, West Wales; School of Biological Sciences, University of Wales: Bangor, UK, 2007; p. 116.

25. Hernandez-Milian, G.; Berrow, S.; Santos, M.B.; Reid, D.; Rogan, E. Insights into the Trophic Ecology of Bottlenose Dolphins (Tursiops truncatus) in Irish Waters. Aquat. Mamm. 2015, 41, 226-239. [CrossRef]

26. Hastie, G.D.; Wilson, B.; Wilson, L.J.; Parsons, K.M.; Thompson, P.M. Functional mechanisms underlying cetacean distribution patterns: Hotspots for bottlenose dolphins are linked to foraging. Mar. Biol. 2004, 144, 397-403. [CrossRef]

27. Berrow, S.D.; Holmes, B.; Kiely, O.R. Distribution and Abundance of Bottle-Nosed Dolphins Tursiops truncatus (Montagu) in the Shannon Estuary. Biol. Environ. Proc. R. Ir. Acad. 1996, 96B, 1-9.

28. Berrow, S.D. Winter distribution of Bottle-nosed Dolphins (Tursiops truncatus (Montagu)) in the inner Shannon Estuary. Ir. Nat. J. 2009, 30, 35-39.

29. O'Brien, J.; Beck, S.; Wall, D.; Pierini, A.; Hanbsen, S. Marine Mammals and Megafauna in Irish Waters-Behavior, Distribution and Habitat Use. Work Package 2: Developing Acoustic Monitoring Techniques; PReCAST Final Report; Marine Research Sub-Programme 2007-2013; Marine Institute: Oranmore, Ireland, 2013; p. 205.

30. Robbins, J.R.; Brandecker, A.; Cronin, M.; Jessopp, M.; McAllen, R.; Culloch, R. Handling dolphin detections from C-PODs, with the development of acoustic parameters for verification and the exploration of species identification possibilities. Bioacoustics 2016, 25, 99-110. [CrossRef]

31. Carlstrom, J. Diel Variation in Echolocation Behavior of Wild Harbor Porpoises. Mar. Mammal Sci. 2005, 21, 1-12. [CrossRef]

32. Leeney, R.H.; Carslake, D.; Elwen, S.H. Using static acoustic monitoring to describe echolocation behavior of heaviside's dolphins (Cephalorhynchus heavisidii) in Namibia. Aquat. Mamm. 2011, 37, 151-160. [CrossRef]

33. Madsen, P.T.; Johnson, M.P.; de Soto, N.A.; Zimmer, W.M.X.; Tyack, P.L. Biosonar performance of foraging beaked whales (Mesoplodon densirostris). J. Exp. Biol. 2005, 208, 181-194. [CrossRef] [PubMed]

34. Todd, V.L.G.; Pearse, W.D.; Tregenza, N.C.; Lepper, P.A.; Todd, I.B. Diel echolocation activity of harbour porpoises (Phocoena phocoena) around North Sea offshore gas installations. ICES J. Mar. Sci. 2009, 66, 734-745. [CrossRef]

35. Akaike, H. Information theory as an extension of the maximum likelihood principle. In Second International Symposium on Information Theory; Petrov, B.N., Csáki, F., Eds.; Akadémiai Kiadó: Budapest, Hungary, 1973; pp. 267-281.

36. Heiberger, R.M. HH: Statistical Analysis and Data Display: Heiberger and Holland. R Package Version 3.1-43. 2020. Available online: https: / CRAN.R-project.org/package=HH (accessed on 5 January 2021).

37. Feingold, D.; Evans, P. Bottlenose dolphin and harbour porpoise monitoring in Cardigan Bay and Pen Llyn a'r Sarnau Special Areas of Conservation. Sea Watch Found. Interim Rep. 2013, 86.

38. Heithaus, M.R.; Dill, L.M. Food Availability and Tiger Shark Predation Risk. Ecology 2002, 83, 480-491.

39. Irvine, A.B.; Scott, M.D.; Wells, R.S.; Kaufmann, J.H. Movements and activities of the Atlantic bottlenose dolphin, Tursiops truncatus, near Sarasota, Florida. Fish. Bull. 1981, 79, 671-688.

40. Wilson, B.; Thompson, P.M.; Hammond, P.S. Habitat use by bottlenose dolphins: Seasonal distribution and stratified movement patterns in the Moray Firth, Scotland. J. Appl. Ecol. 1997, 34, 1365-1374. [CrossRef]

41. Pena, A.V. Temporal Changes in Site Usage by Bottlenose Dolphins (Tursiops truncatus) in New Quay Bay, Wales; School of Ocean Sciences, University of Wales: Bangor, UK, 2014.

42. Went, A.J. Salmon of the River Shannon in 1946 and 1947. ICES J. Mar. Sci. 1950, 16, 341-357. [CrossRef]

43. Mendes, S.; Turrell, W.; Lütkebohle, T.; Thompson, P. The influence of the tidal cycle and a tidal intrusion front on the spatiotemporal distribution of the bottlenose dolphin, Tursiops truncatus, in a narrow estuarine channel, Scotland. Mar. Ecol. Prog. Ser. 2002, 239, 221-229. [CrossRef]

44. Pierpoint, C. Harbour porpoise (Phocoena phocoena) foraging strategy at a high energy, near-shore site in south-west Wales, UK. J. Mar. Biol. Assoc. UK 2008, 88, 1167-1173. [CrossRef]

45. Bowditch, N. Chapter 9: Tides and Tidal Current. In The American Practical Navigator; Lighthouse Press: Fairfield, NJ, USA, 2002; p. 896.

46. Brager, S. Diurnal and seasonal behavior patterns of bottlenose dolphins (Tursiops truncatus). Mar. Mammal Sci. 1993, 9, 434-438. [CrossRef]

47. Hanson, M.T.; Defran, R.H. The behavior and feeding ecology of the Pacific coast bottlenose dolphin, Tursiops truncatus. Aquatic Mamm. 1993, 19, 127.

48. Harzen, S. Habitat use by the bottlenose dolphin (Tursiops truncatus) in the Sado estuary, Portugal. Aquat. Mamm. 1998, 24, 117-128.

49. Alford, L. The Occurrence and Foraging Activity of Bottlenose Dolphins and Harbour Porpoises in Cardigan Bay SAC, Wales; University of Wales: Bangor, UK, 2005.

50. Day, J.R.; Defran, R.H. Nocturnal activity of Pacific coast bottlenose dolphins (Tursiops truncatus) in California. In Abstracts-Eleventh Biennial Conference on the Biology of Marine Mammals; Society for Marine Mammalogy: Lawrence, KS, USA, $1995 ;$ p. 29.

51. Wartzok, D.; Popper, A.N.; Gordon, J.; Merrill, J. Factors Affecting the Responses of. Mar. Technol. Soc. J. 2003, 37, 6-15. [CrossRef]

52. New, L.F.; Harwood, J.; Thomas, L.; Donovan, C.; Clark, J.S.; Hastie, G.; Thompson, P.M.; Cheney, B.; Scott-Hayward, L.; Lusseau, D. Modelling the biological significance of behavioral change in coastal bottlenose dolphins in response to disturbance. Funct. Ecol. 2013, 27, 314-322. [CrossRef]

53. Noren, D.P.; Holt, M.M.; Dunkin, R.C.; Thometz, N.M.; Williams, T.M. Comparative and cumulative energetic costs of odontocete responses to anthropogenic disturbance. Proc. Meet. Acoust. 2017, 27, 040011. 